\title{
Case Reports of Complex Post Traumatic Stress Disorder: Based on Psychological Assessments
}

\author{
Ye-jin Kwon ${ }^{1}$ and Eun-ah Noh ${ }^{2}$ \\ ${ }^{1}$ Department of Psychology, Korea University, Seoul, Korea \\ 2Department of Psychiatry, Asan Medical Center, Seoul, Korea
}

\author{
복합성 외상 후 스트레스 장애에 대한 증례 보고: 심리학적 평가를 중심으로 \\ 권예진 ${ }^{1} \cdot$ 노은아 ${ }^{2}$ \\ 고려대학교 심리학과, ${ }^{1}$ 서울아산병원 정신건강의학과 ${ }^{2}$
}

The growing interest in the prolonged and repeated trauma and its consequences over the past few years has led to the recent inclusion of the Complex post-traumatic stress disorder (PTSD) in International Classification of Diseases, version 11 (ICD-11). The Complex PTSD not only includes core symptoms of PTSD but also includes three additional symptoms: affective dysregulation, negative self-concept, and interpersonal hardship. These new symptoms, however, are perceived as personality traits rather than as the sequelae of complex trauma. Thus, this misconception can lead to the stigmatization of the survivors and influence therapists with diagnosis bias. To prevent such misconception from occurring, the authors present psychological assessments on three Complex PTSD patients so that therapists can gain a better understanding of Complex PTSD and make the proper diagnosis and treatment.

Psychoanalysis 2020;31(4):98-105

KEY WORDS: Complex PTSD $\cdot$ Trauma $\cdot$ Affect $\cdot$ Self.

Received: July 5, 2020 Revised: September 16, 2020 Accepted: September 21, 2020

Address for correspondence: Eun-ah Noh, MA

Department of Psychiatry, Asan Medical Center, 88 Olympic-ro 43-gil, Songpa-gu, Seoul 05505, Korea

Tel: +82-2-3010-3407, Fax: +82-2-485-8381, E-mail: philozzolla@gmail.com

\section{서 론}

심리적 외상(trauma)에 대한 인식은 전쟁의 역사와 더불 어 변모해 왔다. 제 1,2 차 세계대전 당시, 전쟁에 참가한 다수 의 군인들이 무력감, 불안, 신경과민 등의 증상들을 보고하 였다. 처음에는 이를 포탄에 의한 뇌 손상의 결과인 것으로 여겼지만 그보다는 심리적 외상과 관련이 깊다는 인식이 싹 트기 시작했고, 시간이 흐르면서 증상들이 개인의 도덕성 결 여나 열등함으로부터 기인한다는 시각에서도 점차 벗어났다 (Gersons와 Carlier 1992; Crocq와 Crocq 2000; Herman 2015). 베트남 전쟁 이후에는 전쟁으로 인한 심리적 외상에 대해 더욱 방대한 양의 연구들이 축적되었고, 마침내 1980 년, 미국정신의학회는 외상 후 스트레스 장애(post-traumat-

This is an Open Access article distributed under the terms of the Creative Commons Attribution Non-Commercial License (https://creativecommons.org/licenses/by-nc/4.0) which permits unrestricted non-commercial use, distribution, and reproduction in any medium, provided the original work is properly cited. ic stress disorder, PTSD)를 Diagnostic and Statistical Manual of Mental Disorders-third edition(DSM-III)의 공식 진 단 범주로 포함하였다(Egendorf 1981; Herman 2015).

외상의 역사는 1970 년대 여성해방주의 운동을 기점으로 또 한 번의 변곡점을 맞이하였다(Herman 2015). 비교적 사 적인 영역으로 치부되었던 가정 폭력, 아동 학대, 성 폭력 등 에 대한 문제의식이 수면 위로 떠오르면서 개인의 성격 전반 에까지 영향을 미칠 수 있는 만성적인 외상에 대한 관심 또 한 증가하였다. 이에, Herman(1992)은 "복합성 외상 후 스트 레스 장애(complex post-traumatic stress disorder, complex $\mathrm{PTSD})$ "라는 진단적 개념을 제시하여 지속적이고 반복적인 외상을 겪은 이들에게서 나타나는 정서 조절의 어려움, 성격 변화 등을 설명하였고, 2018년에는 PTSD의 핵심 증상과 함 께 정서, 자기(self), 대인관계 영역에서의 지속적인 장해를 포함하는 Complex PTSD가 International Classification of Diseases, version 11(ICD-11)에 정식으로 등재되었다(Maercker 등 2013; Brewin 등 2017). 
복합적인 외상 및 이에 따른 증상들에 대한 관심이 높아 짐에 따라, 여러 연구자들은 complex PTSD가 별개의 진단 적 개념으로서 갖는 타당성을 입증하고자 다양한 노력을 기 울여 왔다. 그럼에도 불구하고 여전히 complex PTSD의 증 상과 많은 부분을 공유하는 두 가지 질환, 즉 $\mathrm{PTSD}$ 와 경계 성 성격 장애(bordeline personality disorder, $\mathrm{BPD}$ )와의 감 별은 중요한 쟁점으로 남아 있다. Complex PTSD에서 나타 나는 정서 조절 장해, 부정적인 자기 개념(self-concept), 대 인관계의 어려움은 흔히 성격장애를 구성하는 주요 영역들 과 중복되며, 특히 $\mathrm{BPD}$ 의 경우 복합성 외상 중 하나인 아동 기 학대 과거력이 빈번히 보고된다는 점에서 주로 비교 선 상에 오른다. 여기에서 우리는 $\mathrm{BPD}$ 의 특성을 살펴 볼 필요 가 있다. 우선 $\mathrm{BPD}$ 는 매우 광범위한 영역을 포괄하는 진단 적 개념이기에 complex PTSD를 비롯한 여러 정신 질환들 과 많은 부분에서 중복되며, 같은 진단을 받은 환자들 내에 서도 이질적인 양상을 보이는 것으로 알려져 있다(Zanarini 등 1998; Lewis와 Grenyer 2009; Kopala-Sibley 등 2012). 고로 $\mathrm{BPD}$ 가 하나의 독립된 진단적 개념으로서 타당한지에 대해 이견이 있어 왔고(Aronson 1985; Lewis와 Grenyer 2009; Becker 2000), complex PTSD와 BPD가 띠는 유사성 또한 일차적으로는 $\mathrm{BPD}$ 가 지니는 광범위성, 이질성의 맥락 에서 생각해 볼 수 있겠다. 더욱이 초기의 외상 경험 외에도 유전적, 생물학적 관련성과 같은 다양한 요인들이 경계성 성 격 형성에 기여할 수 있다는 연구들이 축적되면서(Siever와 Davis 1991; Distel 등 2008; King-Casas 등 2008; Lewis와 Grenyer 2009), BPD와 complex PTSD가 “외상 경험”이라 는 병인론적 측면에서 유사하다는 주장도 힘을 잃고 있다.

이에 비해 complex PTSD와 그 원인이 되는 복합성 외상 과의 관련성은 비교적 분명한 것으로 나타난다. 잠재 프로파 일 분석(Latent profile analysis)을 이용한 연구에 따르면 단 일 외상 사건이 PTSD를 강하게 예측한 반면, complex PTSD 는 만성적인 외상에 의해 더 높게 예측되었으며 PTSD보다 심 각한 손상과 관련이 있는 것으로 나타났다(Cloitre 등 2013). 이러한 분석 결과는 $\mathrm{BPD}$ 환자들을 포함시켰을 때에도 거의 동일하게 나타나, 두 장애가 $\mathrm{BPD}$ 의 동반이환 여부와는 무 관하게 안정성을 지니는 독립된 질환일 가능성을 시사했다. Thomaes 등(2013)이 진행한 뇌 영상 연구에서는 complex PTSD 환자들의 우측 해마(hippocampus) 및 배측 전대상피 질(dorsal anterior cingulate cortex, dorsal ACC)뿐 아니라 우측 안와전두피질(orbitofrontal cortex, $\mathrm{OFC}$ )에서도 회백 질의 농도가 감소하였는데, 이는 전형적인 PTSD가 해마, 편 도체(amygdala), 그리고 전대상피질(anterior ACC)의 더 작 은 볼륨과 관련된다는 기존 근거들과 다른 결과로, 두 장애
의 생리학적 기전이 다를 가능성을 보여주었다. 비록 complex PTSD의 타당성 및 타 질환들과의 감별에 있어 아직까 지 완전히 합치된 결론에 도달하지는 못했지만, $\mathrm{BPD}$ 를 포 함한 성격장애 환자들의 경우 타 질환에 비해 낙인(strigma) 을 얻는 경우가 더 많고 이러한 낙인 효과는 치료에 부정적 인 영향을 미칠 수 있다는 연구들을 고려할 때(Rüsch 등 2008; Magallón-Neri 등 2013; Catthoor 등 2015; Herman 2015; Sheehan 등 2016), 외상의 맥락에서 환자를 보는 시각 이 비단 진단적인 타당성뿐만 아니라 치료적 효용성에 있어서 도 이점을 지닐 것으로 예상된다. 이에, 본 연구자들은 임상가 와 환자 모두에게 새로운 관점과 가능성을 제시하고자 complex PTSD라는 진단적 개념하에서 사례들을 검토하였다.

한편 심리 평가가 환자의 정서 상태와 성격적 특성에 대 한 심층적인 분석을 제시함에도 불구하고, 아직까지 국내외 연구들은 주로 단일한 외상에 초점을 두거나 심리 검사 도구 들 중 일부만을 다루고 있으며 complex PTSD 환자들의 내 적 상태를 종합적으로 평가하고 해석하려는 시도는 부족한 실정이다(Hartman 등 1990; Keh와 Choi 1993; Frueh 등 1995; Lee 등 2004; Reinhard 등 2010). 따라서 본 연구자들 은 복합적인 외상을 경험한 성인 환자 세 명의 정서 및 성격 에 대한 심리 평가 결과를 보고함으로써 진단 및 치료에 기여 할 수 있기를 바란다.

\section{증 례}

2015년 1월부터 2019년 12월까지 서울아산병원 정신건강 의학과 외래에 내원한 환자들 중 위협적인 외상 사건을 반 복하여 경험하고 이에 따른 다양한 정서적 어려움과 개인적, 사회적, 직업적 기능에서의 저하를 보이는 세 가지 사례를 선정하였고, 개인을 식별할 수 있는 모든 정보들을 각색하여 수록하였다. 임상 심리 전문가 또는 전문가의 감독하에 숙련 된 임상 심리 수련생이 심리 평가를 실시하였으며, 평가에 사용된 심리 측정 도구들은 다음과 같다: 미네소타 다면적 인성 검사(Minnesota Multiphasic Personality Inventory-2, MMPI-2), 문장 완성 검사(Sentence Completion Test, SCT), 로르샤하 잉크 반점 검사(Rorschach Inkblot Test, RIT), 주 제 통각 검사(Thematic Apperception Test, TAT), 집-나 무-사람 검사(House-Tree-Person Test, HTP). 본 증례 보 고는 서울아산병원 임상연구심의위원회/기관생명윤리위원 회에서 심의 면제 대상으로 승인되었다(2020-0182).

\section{친척들로부터 감금, 구타를 당했던 $\mathrm{A}$}

$\mathrm{A}$ 는 20대 여성이며, 유학 생활 중 불안감을 호소하여 수 
년 간 투약을 지속해왔다. 약 2년 전부터는 진로 문제 등으 로 부모님과의 다툼이 심해지면서 우울감, 자살사고가 심화 되었을 뿐 아니라 관계사고, 환청 등의 증상들도 발생했다고 한다. 어려서부터 아버지가 어머니를 폭행하는 모습을 수차 례 목격했다는 $\mathrm{A}$ 는 유년기에 부모님이 이혼한 후로 친척 집 을 전전하며 양육자들로부터 감금, 구타를 지속적으로 당해 왔으며, 근래에는 언어적, 신체적 폭력이 심했던 이성 친구 와도 수년 간 관계를 유지해 온 것으로 보고된다. 과거에는 자유 계약으로 어느 정도 경제적 활동이 가능했지만 증상이 시작된 후로는 실직하였고, 실질적인 대인관계 역시 거의 없 는 상태이다. 평소 성격은 조용한 편이나 계획했던 일이 틀 어지면 심하게 욕을 하며 분노를 터뜨릴 때가 있다고 하며, 최근에 증상이 심화된 후로는 별다른 이유 없이 화를 내는 모습이 더욱 빈번해진 것으로 보고된다.

\section{$\mathrm{A}$ 의 심리 검사 결과}

$\mathrm{A}$ 의 경우, RIT에서 피가 나고 훼손된 대상들을 다수 지각 하였고[morbid content(MOR)=7, "피나는 자궁", "피나는 여 자", "피나는 나비", "피나는 게", "피나는 죽은 태", “퍼져서 죽 은 박쥐”, “몸이 반으로 갈라져 죽은 동물”], MMPI의 모든 임 상척도들이 상승하여 인지적, 정서적으로 혼란된 상태가 시사 되었다(MMPI Hs=71T, $\mathrm{D}=66 \mathrm{~T}, \mathrm{Hy}=70 \mathrm{~T}, \mathrm{Pd}=72 \mathrm{~T}, \mathrm{~Pa}=88 \mathrm{~T}$, $\mathrm{Pt}=85 \mathrm{~T}, \mathrm{Sc}=76 \mathrm{~T}, \mathrm{Ma}=69 \mathrm{~T}$ ). 검사 시 “죽은", “검은" 대상들 을 자주 연상하는 등 어둡고 침울한 기분이 뚜렷해 보였고, 평소 지나칠 정도로 자주 손을 씻는다거나 검사자와 대면한 상황에서도 수분 간격으로 크림을 꺼내어 얼굴 등에 바르는 강박적이고 불안한 양상이 관찰되었다. 정보를 처리하고 해 석하는 방식에 있어서는 환경과 최소한의 거리도 유지하지 못한 채 자신의 내적 갈등이나 혼란을 외부 자극에 투사하 는 경향이 두드러졌고(RIT Lambda=0.08), RIT에서 형태가 없는 색채 반응이 주를 이루는 등 정서 지연 능력이 결여되 고 정서 조절에도 실패하는 모습을 보였다 $(\mathrm{FC}=\mathrm{CF}+\mathrm{C}=0: 6$, Pure $\mathrm{C}=5$ ).

$\mathrm{A}$ 는 HTP에서 "가시가 없어서 보호가 안 되는 나무”를 묘 사하는 등 “보호”와 관련된 주제들을 반복적으로 언급하는 동시에, 스스로를 부정적이고 무력한 존재로 지각하는 경향 이 두드러졌다(HTP 집 "도망가지 못하고 가둬진 곳에 사는 사람들”, 여성화 “팔짱을 끼고 있었으면 좋겠다, 옆에 아무 도 없으니까 내가 나를 보호하게”; RIT “발이 4개나 있는데 넘어져서 도망치지 못하는”, “잡혀서 타고 있는 사람”, $\mathrm{EgO}^{-}$ centricity index $=0.23$ ). 더불어 잉크 반점들을 보고 "뭔가 무 섭고 징그러운 것”, “꽃이 뭘 먹으려고 기다리고 있다", “무 서운 동물", "얼굴 모양의 칼"이라고 언급하는 등 외부 대상
들의 태도를 악의적으로 해석하며 지나치게 경계하는 모습 이 나타났고(HTP 인물화 “나를 보고 비웃고 있다”), 공격적 인 운동 반응도 유의미한 수준으로 상승되었다(RIT $A G=3)$. 특히 어머니와 자신이 주로 수동적이고 피해를 당하는 역할 을 해왔던 $\mathrm{A}$ 의 경우, 남녀 간의 역학 관계에 유난히 민감한 태도를 보이며 강하고 지배적인 여성이 되고 싶은 염원을 내 비쳤다(SCT "내가 바라는 여인상은/남자 위, 힘 있는 여자", "남자에 대해서 무엇보다 좋지 않게 생각하는 것은/자기가 여자보다 위라고 생각하는 거").

\section{유년 시절 계모로부터 학대를 당해왔던 B}

$\mathrm{B}$ 는 50대 남성으로, 내원하기 수일 전부터 번개탄을 피우 거나 목을 매는 등 반복적인 자살 시도가 보고되며 현재 극 심한 우울감과 함께 흥미 감소, 과다 수면, 피로감, 무가치감 등을 호소하였다. $\mathrm{B}$ 는 유년기 동안 재혼 가정에서 자라면서 계모로부터 심한 물리적, 정서적 학대를 당해온 것으로 보고 된다(예: 상한 음식을 먹임, 방에 가둠, 이마에 피가 날 정도 로 구타). 평소에는 내성적이고 조용한 성격이나 자존심이 지나치게 세고 고집스러운 성향으로 인해 수년 간 근무했던 근로업체에서 상사 및 동료들과 언쟁 혹은 주먹다짐을 하는 일이 빈번했다고 하며, 최근에는 개인 사업을 준비하다가 경 제적 어려움에 부딪혀 실직하였다. 이성관계의 경우, 결혼 경험이 있으나 환자 및 배우자 모두 감정기복이 심하여 사 소한 일로도 쉽게 다투었다고 하며, 부부싸움을 할 때에는 배우자가 칼로 손목을 긋는 등 자해를 하는 경우도 많았다 고 한다. 현재는 이혼 상태이며, 가족뿐 아니라 지인들과도 별다른 교류 없이 혼자 거주하는 것으로 보고된다.

\section{$\mathrm{B}$ 의 심리 검사 결과}

$\mathrm{B}$ 의 경우 검사 전반에 반응 속도가 느리고 시선을 아래로 떨구고 있어 외견상 에너지 수준이 매우 낮아 보였는데, 검 사상으로도 우울감을 시사하는 지표들이 유의미하게 상승 하였고 무망감, 절망감과 관련된 언급이 잦았다(RIT DEPI=positive; MMPI D=71T, Ma=34T; SCT "언젠가 나 는/비참한 모습이 될 것 같다"). 특히 TAT에서 “자살하는 장 면, 희망이 없으니까 빨리 쉬고 싶을 것 같다”고 연상하는 등 자살사고나 죽음과 관련된 사고가 여실히 드러났으며, 실 제로도 내원 직전에 여러 번 자살을 시도했던 것으로 보고 되었다. 동시에 “핵 공격”과 같이 폭발적인 연상들이나 높은 분노 수준을 암시하는 지표들이 유의미하게 상승한 점을 볼 때, $\mathrm{B}$ 는 울분에 가득 차있을 뿐 아니라 정서적으로 충동적인 상태임을 알 수 있었다(MMPI Pd=75T, RIT “화산 폭발", "입에서 불을 내뿜는 괴물", “핵 공격", $\mathrm{FC}: \mathrm{CF}+\mathrm{C}=0: 4)$. 외부 
자극에 필요 이상으로 의미를 부여하며 민감하게 받아들이 는 특성으로 인해 자신을 둘러싼 상황에 쉽게 압도될 가능 성이 있어 보였고(RIT Lambda=0.09), 수십 년이 지났음에 도 여전히 계모와의 관계 및 학대 경험을 과도하게 반추하 고 몰두하는 양상도 두드러졌다(SCT 어떻게 해서든 잊고 싶은 것은/너무 많은데 단정적으로 말하기 힘들다; 주로 새 어머니와 관련된 기억들이요).

$\mathrm{B}$ 는 SCT에서 자기비하적인 언급을 반복하는 등 스스로 에 대한 긍정적인 시각이나 자기 확신이 매우 부족해 보였 고(RIT Egocentric index=0.17, V=2; SCT "나를 괴롭히는 것은/나의 무능함", "나의 능력은/많이 부족하다", "나의 좋 은 점은/없음"), 타인과의 상호작용에서도 별다른 즐거움을 얻지 못한 채 고립감을 경험하는 듯했다(HTP 집 그림에서 문을 생략하고 창문에 빗금을 추가함; SCT "내가 없을 때 친구들은/친구가 없어서 안 떠올라요", "다른 사람들과 함께 있는 것은/내 머릿속에 고민들 때문에 어울리는 시간이 즐 겁지 않다", “사람들이 나를 피할 때/나도 같이 피한다"; RIT Isolate/R=0.25). 특히 통합된 대상 표상이 내재화되지 않은 상태로 보이는데, 유아적인 수준의 의존 욕구가 강하게 자리하고 있으면서도 대상과의 관계에 대한 기대가 상당히 양가적이고 분열되어 있는 바, 타인에 대해 현실적이고 통합 적인 인상을 형성하며 이를 바탕으로 안정적인 관계를 맺고 유지하는 데는 제한이 많을 것으로 예상되었다(SCT "남자 들은 여자에 대해/위로 받기를 원한다", "임신부를 보면/포 근하다", RIT “두 사람이 사랑하면서도 헤어지는 것, 서로 잡 아 찢는 느낌", $\mathrm{M}-=3$ ).

\section{반복적으로 성적 피해를 경험한 $\mathrm{C}$}

30대 여성인 $\mathrm{C}$ 는 유년기에 부모님의 언어적, 신체적 폭력 (예: 받아쓰기에서 하나 틀릴 때마다 뺨을 때림, 환자에게 물건을 던짐)이 지속되어 왔을 뿐만 아니라 고교 시절 학교 선배들로부터 집단 성폭행을 당한 경험이 있고, 이후에도 남 자친구 혹은 낮선 남성으로부터 반복적으로 성적 피해, 폭력 을 경험해 온 것으로 보고된다. 대학을 졸업한 후에는 간단 한 수공업 자격증을 취득하여 계약직으로 종사하고 있는데, 직장 내에서도 남자 상사로부터 언어적으로 성희롱을 당할 때가 있었다고 한다. 대인관계의 경우, 학령기에 또래로부터 따돌림을 당하는 일이 잦았다고 하며, 현재도 동성 친구들과 의 교류는 많지 않은 것으로 보고된다. 성인이 된 후로는 다 수의 남성, 여성과 무분별하게 성적 관계를 맺어 왔는데, 최 근에 만나기 시작한 연인은 환자의 사생활에 지나치게 간섭 하고(예: 친구들을 만나지 못하게 함, 심리치료를 반대함, 원 하는 옷을 입게 함) 심하게 화를 내는 경향이 있어 다툼이 빈
번하다고 한다. 환자 또한 어려서부터 감정 조절이 어려워 화가 나면 상대에게 심한 욕설을 퍼붓거나 주변 물건들을 부수는 등 폭발적으로 행동할 때가 많았다고 한다.

\section{$\mathrm{C}$ 의 심리 검사 결과}

$\mathrm{C}$ 의 경우, HTP에서 인물들에 대해 주로 "별 생각이 없다" 는 식으로 지나치게 단순한 응답을 하고 여성을 사이보그로 묘사하는 등 감정을 유리시키고 고통스러운 자극들과 거리 를 두려는 노력이 두드러졌다. 그럼에도 불구하고 검사상 우 울하고 무력한 기분, 만족감이 결여된 상태가 되었으며(SCT 언젠가 나는/괴롭지 않을 것이다, 나는/행복해지고 싶다) 지 능검사와 같이 중립적인 자극에조차 자신의 개인적인 경험 과 감정들을 개입시키는 모습으로, 외부와의 객관적인 거리 를 유지하는 것이 쉽지 않아 보였다(RIT Lambda=0.21). 특 히 외상과 관련된 악몽과 이로 인한 정서적 고통이 심한 것 으로 보고한 가운데, 십여 년이 지났음에도 여전히 과거의 부정적인 경험들을 반추하는 양상이 두드러졌다(SCT "내가 정말 행복하려면/과거의 기억들이 지워져야 한다", "어떻게 해서든 잊고 싶은 것은/과거다", "나에게 가장 문제되는 것 은/과거를 곱씹으며 괴로워하는 것”, “나를 괴롭히는 것은/ 과거의 기억에서 벗어나지 못하는 것”). 그러면서도 남성화 를 누드 크로키로 묘사한다거나 색채 중심으로 잉크 반점을 지각하는 등 자극 추구적이고 정서적으로 충동적인 경향이 뚜렷했는데, 이러한 특성과 더불어 자신에 대한 긍정적인 인 식이나 자기 존중감이 매우 부족하여, 오히려 일탈적인 성적 행위나 자해와 같은 자기파괴적인 행동에 몰두할 소지가 있 어 보였다(RIT “솦 속에 폭포가 흐르는 것”, $\mathrm{FC}: \mathrm{CF}+\mathrm{C}=1: 7$, Pure $\mathrm{C}=2$, Egocentric index=0.06; $\mathrm{SCT}$ "나의 좋은 점은/없 다. 굳이 따지자면 예쁜 척을 하지 못하는 것”). 특히 “사이 보그 여성", "여성을 보는 (누드의) 남성[HTP]"과 같은 연상 들을 미루어 볼 때, 피검자는 이성과의 관계에서 자신을 상 대방의 필요 및 욕구의 대상으로서만 존재하는, 무기력하고 수동적인 역할과 동일시하거나 혹은 남성의 관음증적 대상 으로서의 여성성에만 몰두하면서, 남성과 수직적인 관계를 형성할 가능성이 높아 보이고 이는 착취적인 이성관계의 반 복에 기여하는 바가 있지 않나 짐작된다. 그러나 초기 대상 과의 관계에서 신뢰감을 형성하지 못한 피검자가, 이러한 병 리적인 형태의 이성관계를 제외하고는 대인관계에서 친밀 한 접촉과 신뢰를 형성하지 못하고 갈등이 반복되는 것 같 은데, RIT 결과 또한 피검자의 소외되고 고립된 사회적 관 계를 시사한다(Isolate/R=0.29; SCT "다른 사람들과 함께 있 는 것은/즐겁지 않은 경우가 많다", "나와 같이 일하는 사람 들은 대개/나와 싸우게 된다"). 


\section{고 찰}

앞서 살펴본 증례들은 모두 오랜 기간 반복되었던 가정 폭력, 아동 학대, 성폭력과 같은 복합적인 외상 경험을 포함 하는데, RIT 결과 신체적, 성적 학대를 경험한 생존자들에게 서 자주 보고되는 병리적인 내용(MOR), 피(blood) 또는 해 부(anatomy) 관련 내용의 반응들이 다수 나타났다(van der Kolk와 Ducey 1989; Shapiro 등 1990; Kamphuis 등 2000). 검사 시기가 실제 외상 경험으로부터 최소 십여 년이 지난 시점이었음에도 여전히 과거의 부정적인 경험들을 과도하 게 반추하거나 때로는 자신의 의지와는 무관하게 외상과 관 련된 기억에 매몰되었으며, 중립적인 자극에도 지나치게 감 정을 이입하고 내적 갈등을 투사함으로써 자신을 둘러싼 상 황에 쉽게 압도되는 취약한 모습도 관찰되었다. 일부 사례들 에서는 불편감을 유발할 만한 단서들을 회피하고자 외부 자 극과 거리를 두며 감정을 격리(isolation)하려는 시도들도 뚜 렷하였으나, 이러한 방어의 노력에도 불구하고 외상과 관련 된 기억, 악몽, 그리고 불쾌한 감정들로부터 영향을 받고 있었 고, 외상을 경험한 생존자들에게서 자주 관찰되는 우울 및 불 안과 관련된 모습도 두드러졌다(Gilboa-Schechtman과 Foa 2001; Heim과 Nemeroff, 2001; Campbell 등 2007; Ford 등 2012).

다음으로 ICD-11에서 Complex PTSD의 핵심 특징 중 하 나로 기술한 정서 조절 장해를 모든 사례에서 관찰할 수 있 었다. 일례로 RIT에서 잉크반점의 형태보다는 색채를 중심 으로 지각하는 경향이 매우 뚜렷했으며, 이와 같은 색채 우 세 반응들은 정서 및 행동 통제의 어려움, 충동성과 관련이 높은 것으로 밝혀진 바 있다(Townsend 1967; Exner 2003; Weiner 2003). 특히 “핵 공격(사례 B)"과 같이 높은 수준의 분노와 공격성을 암시하는 폭발적인 연상들이 다수 나타났 는데, 관찰과 모방을 통해 부모의 폭력 행동으로부터 공격성 을 학습한다는 사회학습적 관점을 비롯하여 아동학대와 공 격성 간의 관련성을 입증하는 다수의 연구들이 있어 왔다 (Bandura 1974; Kaufman과 Zigler 1989; Herzberger 1983; Ford 등 2010; Vandenberg와 Marsh, 2009). 일찍이 Anna Freud(1936)는 피해자들에게서 나타나는 공격성을 설명하 기 위해 "공격자와의 동일시(identification with the aggressor)"라는 개념을 제안했다. 이는 학대를 당한 사람이 고통 을 극복하기 위해 가해자의 특성을 내사하는 과정이며, 피해 자는 이를 통해 단지 해를 당하기만 하는 무력하고 수동적 인 위치로부터 벗어나 위협을 가하는 주체가 되어 통제감을 가지고 불안이나 고통스러운 감정들을 누그러뜨릴 수 있다 (McWilliams 2011), 때로 생존자들의 공격성은 자기 자신을
향하여, 자살시도, 무분별한 성적 행위와 같은 자기파괴적인 행동으로도 이어진다(van der Kolk 등 1991; Romans 등 1995; Dyer 등 2009; Harford 등 2014). 특히 성장기 동안에 반복적으로 성적 피해를 당해왔던 $\mathrm{C}$ 의 경우, 일탈적이고 무 분별한 성적 행위를 지속하였을 뿐 아니라 그림 검사상으로 도 이성의 모습을 누드 크로키로 그리는 등 성애화(sexualization)의 경향성을 뚜렷하게 보였다. 이는 즉 공포와 정서적 고 통, 압도적인 경험을 흥분으로 전환시키거나 성적 활동 혹은 환상을 통해 회피하려는 무의식적인 시도가 작동하는 것으로, 한편으로는 성적 각성이 살아 있음을 느끼게 하는 수단이 되 기도 한다(McWilliams 2011). Finkelhor과 Browne(1985)은 어린 시절에 성적 학대를 경험한 피해자가 오히려 성적으로 부적절하고 역기능적인 태도를 보이는 현상을 일컬어 외상성 성애화(traumatic sexualization)라고 하였는데, 이는 결과적 으로 재희생자화(revictimization)의 위험성을 높일 수 있다 는 측면에서 자기 파괴적인 행동의 일환이라 볼 수 있다.

Herman(1992)이 지적하였듯이 복합적인 외상은 생존자 들의 자기감(sense of self)을 뒤흔들며, 본 증례들에서도 이 와 관련된 특징들이 공통적으로 나타났다. 이들은 자신감이 매우 부족하고 스스로에 대해 부정적인 견해를 가지고 있었 는데, 검사상 자기비하적인 언급이 자주 반복되었으며 스스 로에 대한 관심 및 자기 존중감(self-esteem)을 반영하는 것 으로 알려진 RIT의 자아중심성 지표(The Egocentricity Index) 또한 유의미한 수준으로 낮았다(Exner 2003; Weiner 2003). 생존자들에게서 나타난 "자기 비난(turning against the self)"의 기제는 통제할 수 없는 고통스러운 현실 속에서 주로 발생하는데, 자신의 힘으로 극복할 수 없는 환경이나 외부 대상을 비판하기보다 차라리 스스로를 탓함으로써 최 소한의 안전감을 유지하려는 시도로서 이해해 볼 수 있다 (Freud 1936; McWilliams 2011). 또한 자기 자신을 무능하 고 무력한 대상으로 지각하는 모습은, 아동 학대 생존자들이 달리 피할 곳을 찾지 못한 채 부모의 절대적인 권력과 폭력 에 바짝 엎드림으로써 적응하려 했던 노력과도 닮아 있었다 (Herman 2015). 이처럼 오랜 기간 지속된 학대는 아동으로 부터 예측 가능성과 통제력을 앗아가고, 이는 자기 효능감과 자신에 대한 연속적인 감각을 약화시키는 요인으로 작용한 다(Allen 2008).

타인을 인식하고 외부 세계와 상호작용하는 방식에 있어 서도 눈여겨볼 만한 점들을 발견하였다. 이들의 대상표상은 대체로 부정적이고 통합이 되지 못한 채 분열(spilitting)된 양상을 띠기도 했으며, 내면의 부정적인 생각이나 충동들을 외부로 투사(projection)하여 타인의 의도를 악의적으로 해 석하는 경향도 두드러졌다. 동시에 이면에는 다른 사람으로 
부터 도움이나 위안을 얻고자 하는 의존성이 강하게 시사되 었고, 무엇보다도 Freud 등(1990)이 주장했던 반복 강박 (repetition coumpulsion)에 사로잡힌 듯, 가학적인 대상을 추구하고 관계를 유지하는 병리적인 모습이 공통적으로 시 사되고 있다. 통제-숙달 이론(control-mastery theory)에서 는 이처럼 외상 경험과 유사한 상황을 창조하는 것이 외상 을 숙달(mastering trauma)하기 위한 시도라고 보았는데 (Weiss 1988; Suffridge 1991; McWilliams 2011; Fimiani 등 2020), 이러한 노력이 늘 성공적인 것은 아니며 오히려 병리 적인 대상 관계를 반복함으로써 더 큰 고통과 희생을 치르 게 될 위험이 따른다(Fairbairn 1943; Shainess 1987; van der Kolk와 Ducey 1989; Corradi 2009). 본 사례들에서도 보 호를 받고자 하는 의식적인 의도와는 달리 도리어 위험에 쉽게 노출되는 경향이 나타났고, 별다른 친밀한 관계 없이 고립된 생활을 하거나 갈등 상황에 휘말리는 경우도 많았다. 폭력적인 아버지로 인해 남성의 힘이나 지배에 대한 혐오적 인 태도가 크면서도 폭력적인 이성과의 관계를 지속하는 A, 스스로를 남성의 성적 대상화하는 경향성이 암시되는 가운 데 지나치게 자신을 통제하는 이성과 관계를 지속하는 $\mathrm{C}$ 역 시 반복 강박의 심리적 메커니즘이 작용하고 있을 가능성이 높아 보인다. 또한 $\mathrm{B}$ 의 경우 친밀한 관계 패턴을 좀 더 살펴 볼 필요는 있겠으나, 부인의 자해 행동이나 결혼이 파국에 이르게 된 결과에는 병리적인 대상 선택 혹은 병리적인 관 계를 촉발하는 무의식적인 역동이 작동한 것 같고, 이후의 관계에서도 이러한 양상이 반복될 여지를 고려하지 않을 수 없겠다. 그리고 이렇게 병리적인 대인관계를 반복하는 것은 그 자체로 우울감, 외로움과 같은 많은 정서적 고통을 야기 할 뿐 아니라 사회적 지지 체계와 연결될 기회를 박탈함으 로써 회복을 저해하는 요인이 된다(Herman 2015).

한편 저자들은 분석 과정에서 정서, 자기(self), 대인관계 영역에서의 어려움을 보이는 본 사례들을 성격장애로 진단 할 수 있는지 검토하였고, 그중에서도 complex PTSD와 유 사한 특징들을 공유하는 $\mathrm{BPD}$ 와의 감별에 중점을 두었다.

The Diagnostic and Statistical Manual of Mental Disorders, Fifth Edition (DSM-5)을 바탕으로 $\mathrm{BPD}$ 를 진단하기 위해 서는 아홉 가지 준거들 중 다섯 개 이상을 충족해야 하는데, 본 사례들은 증상의 수나 정도에 있어서 이에 못 미치는 것 으로 나타났다. $\mathrm{BPD}$ 와 가장 유사한 양상을 보인 $\mathrm{B}$ 마저도 유기에 대한 두려움이나 해리 증상, 물질 남용처럼 손상 가 능성이 있는 충동적인 행동들을 보고하지는 않았으며 정체 성 및 정동 영역에서의 어려움 또한 $\mathrm{BPD}$ 에 준하는 심각성 으로 고려하기에는 제한이 있었다.

오히려 본 사례들에서 나타난 여러 특징들은 선행 연구에
서 밝혀진 complex PTSD의 프로파일과 상당 부분 일치했 다. Shim 등(2004)에 따르면 복합성 외상을 경험한 생존자 들의 로샤 반응에서는 다음의 네 가지 특징들이 나타난다. 1) 문제 해결과 대처방식의 비효율성, 2) 지각의 부정확성, 3) 정서 조절의 어려움, 4) 침투적인 외상 관련 기억. 세 가지 사례들에서 공통적으로 관찰되었던 낮은 Lambda 값은 외부 자극과 거리를 두지 못하고 필요 이상의 자원으로 대처하는 비효율성을 시사하며, $\mathrm{X}-\%$ 의 상승은 지각의 왜곡을, 다수의 color-form(CF)과 Pure C 반응들은 정서 조절의 어려움을 반영한다고 볼 수 있다. 또한 병리적 내용(morbid), 해부 관 련 내용(anatomy), 피 반응(blood)은 외상과 관련된 기억이 침 투적임을 뜻하며, 이는 외상 관련 내용 지표(Trauma Content Index, TC/R)의 하위 변인들로도 잘 알려져 있다(Armstrong 과 Loewenstein 1990). 이와 대조적으로, 교통사고와 같은 단 일 외상 사건을 경험한 PTSD 환자들에게서는 주로 MMPI의 1-3 코드가 상승하며 신체 증상에 몰두하는 신체화의 경향 성이 관찰되었는데(Keh와 Choi 1993; Lee 등 2004), 본 사례 들에서는 이러한 양상이 뚜렷하게 나타나지 않아, 심리 검사 상 단일 외상과 복합 외상 간에 차이가 있음을 시사하였다.

\section{결 론}

지금까지 복합적인 외상을 경험한 환자들의 종합적인 심 리평가 결과를 살펴보았다. 자기 보고식 검사 및 투사 검사 결과, 외상과 관련된 연상들과 함께 정서 조절 장해, 자기 지 각의 변화, 대인 관계의 어려움을 시사하는 반응들이 다수 나타났으며, 이는 ICD-11에 수록된 Complex PTSD의 특징 들을 두루 반영하고 있다. 본 사례 보고는 국내에서 활발히 연구되지 않은 복합성 외상이라는 영역을 좀 더 심층적인 수준에서 살펴보았다는 점에서 의의가 있다. 다만, 사례의 수가 적고 성인 환자들에만 국한되었다는 점에서 아쉬움이 남는다. 향후에는 복합적인 외상 환자들에 대한 보다 광범위 한 연구가 이루어지기를 기대하는 바이다.

\section{Acknowledgments}

None

\section{Conflicts of Interest}

The authors have no potential conflicts of interest to disclose.

\section{Author Contributions}

Conceptualization: all authors. Data curation: Ye-jin Kwon. Supervision: Eun-ah Noh. Writing — original draft: Ye-jin Kwon. Writing — review \& editing: all authors.

\section{ORCID iDs}

Ye-jin Kwon https://orcid.org/0000-0001-7633-5067 
Eun-ah Noh https://orcid.org/0000-0003-1863-6392

\section{REFERENCES}

Allen JG. Coping with trauma: hope through understanding. Arlington: American Psychiatric Publishing;2008. p.3-221.

Armstrong JG, Loewenstein RJ. Characteristics of patients with multiple personality and dissociative disorders on psychological testing. $\mathrm{J}$ Nerv Ment Dis 1990:178:448-454.

Aronson TA. Historical perspectives on the borderline concept: a review and critique. Psychiatry 1985;48:209-222.

Bandura A. Behavior theory and the models of man. American Psychologist 1974;29:859.

Becker D. When she was bad: borderline personality disorder in a posttraumatic age. Am J Orthopsychiatry 2000;70:422-432.

Brewin CR, Cloitre M, Hyland P, Shevlin M, Maercker A, Bryant RA, et al. A review of current evidence regarding the ICD-11 proposals for diagnosing PTSD and complex PTSD. Clin Psychol rev 2017;58:1-15.

Campbell DG, Felker BL, Liu CF, Yano EM, Kirchner JE, Chan D, et al. Prevalence of depression-PTSD comorbidity: implications for clinical practice guidelines and primary care-based interventions. J Gen Intern Med 2007;22:711-718.

Catthoor K, Feenstra DJ, Hutsebaut J, Schrijvers D, Sabbe B. Adolescents with personality disorders suffer from severe psychiatric stigma: evidence from a sample of 131 patients. Adolesc Health Med Ther 2015;6:81-89.

Cloitre M, Garvert DW, Brewin CR, Bryant RA, Maercker A. Evidence for proposed ICD-11 PTSD and complex PTSD: a latent profile analysis. Eur J Psychotraumatol 2013 May 15 [Epub]. https://doi. org/10.3402/ejpt.v4i0.20706.

Corradi RB. The repetition compulsion in psychodynamic psychotherapy. J Am Acad Psychoanal Dyn Psychiatry 2009;37:477-500.

Crocq MA, Crocq L. From shell shock and war neurosis to posttraumatic stress disorder: a history of psychotraumatology. Dialogues Clin Neurosci 2000;2:47.

Distel MA, Trull TJ, Derom CA, Thiery EW, Grimmer MA, Martin NG, et al. Heritability of borderline personality disorder features is similar across three countries. Psychol Med 2008;38:1219-1229.

Dyer KF, Dorahy MJ, Hamilton G, Corry M, Shannon M, MacSherry A, et al. Anger, aggression, and self-harm in PTSD and complex PTSD. J Clin Psychol 2009;65:1099-1114.

Egendorf A. Legacies of Vietnam: comparative adjustment of veterans and their peers: a study. Washington: US Government Printing Office; 1981. p.1-122.

Exner Jr JE. The Rorschach: a comprehensive system: basic foundations. Vol. 1. New York: John Wiley \& Sons;2003. p.385-643.

Fairbairn WRD. The repression and the return of bad objects (with special reference to the 'war neuroses'). Br J Med Psychol 1943;19:327341.

Fimiani R, Gazzillo F, Fiorenza E, Rodomonti M, Silberschatz G. Traumas and their consequences according to control-mastery theory. Psychodyn Psychiatry 2020;48:113-139.

Finkelhor D, Browne A. The traumatic impact of child sexual abuse: a conceptualization. Am J Orthopsychiatry 1985;55:530-541.

Ford JD, Chapman J, Connor DF, Cruise KR. Complex trauma and aggression in secure juvenile justice settings. Crim Justice Behav 2012; 39:694-724.

Ford JD, Fraleigh LA, Connor DF. Child abuse and aggression among seriously emotionally disturbed children. J Clin Child Adolesc Psychol 2010;39:25-34.

Freud A. The ego and the mechanisms of defense. New York: International Universities Press;1936. p.109-121.

Freud S. Beyond the pleasure principle. In: Gay P, Strachey J. Beyond the pleasure principle. New York: W.W. Norton \& Company;1990. p.1-78. (Original work published 1920)

Frueh BC, Leverett JP, Kinder BN. Interrelationship between MMPI-2 and Rorschach variables in a sample of Vietnam veterans with PTSD. J Pers Assess 1995;64:312-318.

Gersons BP, Carlier IV. Post-traumatic stress disorder: the history of a recent concept. Br J Psychiatry 1992;161:742-748.

Gilboa-Schechtman E, Foa EB. Patterns of recovery from trauma: the use of intraindividual analysis. J Abnorm Psychol 2001;110:392-400.

Harford TC, Yi HY, Grant BF. Associations between childhood abuse and interpersonal aggression and suicide attempt among US adults in a national study. Child Abuse Negl 2014;38:1389-1398.

Hartman WL, Clark ME, Morgan MK, Dunn VK, Fine AD, Perry GG $\mathrm{Jr}$, et al. Rorschach structure of a hospitalized sample of Vietnam veterans with PTSD. J Pers Assess 1990;54:149-159.

Heim C, Nemeroff CB. The role of childhood trauma in the neurobiology of mood and anxiety disorders: preclinical and clinical studies. Biol Psychiatry 2001;49:1023-1039.

Herman JL. Complex PTSD: a syndrome in survivors of prolonged and repeated trauma. J Trauma Stress 1992;5:377-391.

Herman JL. Trauma and recovery: the aftermath of violence--from domestic abuse to political terror. New York: Basic Books;2015. p.25-222.

Herzberger SD. Social cognition and the transmission of abuse. In: Finkelhor D, Gelles RJ, Hotaling GT, Straus MA. The dark side of families: current family violence research. Newbury Park, London, and New Delhi: SAGE Publications;1983. p.317-329.

Kamphuis JH, Kugeares SL, Finn SE. Rorschach correlates of sexual abuse: trauma content and aggression indexes. J Pers Assess 2000;75: 212-224.

Kaufman J, Zigler E. The intergenerational transmission of child abuse. In: Cicchetti D, Carlson V. Child maltreatment: theory and research on the causes and consequences of child abuse and neglect. Cambridge: Cambridge University Press;1989. p.129-150.

Keh YJ, Choi JY. Minnesota multiphasic personality inventory (MMPI) responses of posttraumatic stress disorder patients. Korean J Clin Psychol 1993;12:30-40.

King-Casas B, Sharp C, Lomaz-Bream L, Lohrenz T, Fonagy P, Montague PR. The rupture and repair of cooperation in borderline personality disorder. Science 2008;321:806-810.

Kopala-Sibley DC, Zuroff DC, Russell JJ, Moskowitz DS, Paris J. Understanding heterogeneity in borderline personality disorder: differences in affective reactivity explained by the traits of dependency and self-criticism. J Abnorm Psychol 2012;121:680-691.

Lee JH, Kim YS, Aan CY. Study on MMPI of the group of PTSD patients due to war and the group of PTSD patients due to accidents. Korean J Clin Psychol 2004;23:221-229.

Lewis KL, Grenyer BF. Borderline personality or complex posttraumatic stress disorder? An update on the controversy. Harv Rev Psychiatry 2009; 17:322-328.

Maercker A, Brewin CR, Bryant RA, Cloitre M, Reed GM, van Ommeren M, et al. Proposals for mental disorders specifically associated with stress in the International Classification of Diseases-11. Lancet 2013;381:1683-1685.

Magallón-Neri E, Forns M, Canalda G, De la Fuente JE. 542-Stigmatization, personality disorders and adolescence. Eur Psychiatry 2013; 28(S1):1.

McWilliams N. Psychoanalytic diagnosis: understanding personality structure in the clinical process. New York: The Guilford Press;2011. p.121-122, 138, 144-145, 267-288.

Reinhard MJ, Wolf G, Cozolino L. Using the MMPI to assess reported cognitive disturbances and somatization as a core feature of complex PTSD. J Trauma Dissociation 2010;11:57-72.

Romans SE, Martin JL, Anderson JC, Herbison GP, Mullen PE. Sexual abuse in childhood and deliberate self-harm. Am J Psychiatry 
1995; 152:1336-1342.

Rüsch N, Schiel S, Corrigan PW, Leihener F, Jacob GA, Olschewski $\mathbf{M}$, et al. Predictors of dropout from inpatient dialectical behavior therapy among women with borderline personality disorder. J Behav Ther Exp Psychiatry 2008;39:497-503.

Shainess N. Masochism-or self-defeating personality? J Pers Disord 1987;1:174-177.

Shapiro JP, Leifer M, Martone MW, Kassem L. Multimethod assessment of depression in sexually abused girls. J Pers Assess 1990; 55:234248.

Sheehan L, Nieweglowski K, Corrigan P. The stigma of personality disorders. Curr Psychiatry Rep 2016;18:11.

Shim EJ, Min SG, Lee JH, Kim JY, Song WY. Rorschach protocols from Japanese military comfort women. Korean J Clin Psychol 2004;23: 169-187.

Siever LJ, Davis KL. A psychobiological perspective on the personality disorders. Am J Psychiatry 1991;148:1647-1658.

Suffridge DR. Survivors of child maltreatment: diagnostic formulation and therapeutic process. Psychotherapy: Theory, Research, Practice, Training 1991;28:67.

Thomaes K, Dorrepaal E, Draijer N, de Ruiter MB, Elzinga BM, Sjo- erds $\mathbf{Z}$, et al. Increased anterior cingulate cortex and hippocampus activation in Complex PTSD during encoding of negative words. Soc Cogn Affect Neurosci 2013;8:190-200.

Townsend J. The relation between Rorschach signs of aggression and behavioral aggression in emotionally disturbed boys. J Proj Tech Pers Assess 1967;31:13-21.

Vandenberg B, Marsh U. Aggression in youths: child abuse, gender and SES. N Am J Psychol 2009;11:437-441.

van der Kolk BA, Ducey CP. The psychological processing of traumatic experience: Rorschach patterns in PTSD. J Trauma Stress 1989;2:259274.

van der Kolk BA, Perry JC, Herman JL. Childhood origins of self-destructive behavior. Am J Psychiatry 1991;148:1665-1671.

Weiner IB. Principles of Rorschach interpretation. Mahwah: Lawrence Erlbaum Associates, Inc., Publishers;2003. p.142-221.

Weiss J. Testing hypotheses about unconscious mental functioning. Int J Psychoanal 1988;69(Pt 1):87-95.

Zanarini MC, Frankenburg FR, Dubo ED, Sickel AE, Trikha A, Levin A, et al. Axis I comorbidity of borderline personality disorder. Am J Psychiatry 1998;155:1733-1739. 